\title{
Avaliação de uma experiência de gestão hospitalar participativa no âmbito do SUS: produção de saúde, sujeitos e coletivos
}

Evaluation of a participatory hospital management experience in the national health service SUS: production of health, individual and collective

Adriana Diniz de Deus ${ }^{1}$, Elza Machado de Melo²

\begin{abstract}
RESUMO O presente artigo trata-se de estudo de caso com objetivo de avaliar a experiência de gestão da Maternidade Pública Municipal de Betim (MG), de 2009 a 2011, por meio de análise de intervenção, que investiga se objetivos e metas propostos pela experiência foram alcançados. A metodologia consistiu de análise documental e grupos focais. A análise pautou-se na hermenêutica crítica. A Maternidade adotou, no período estudado, um modelo de gestão entrelaçado ao modelo de cuidado, com criação de espaços de escuta e de responsabilização pelos processos de trabalho. Este estudo mostrou que, apesar dos limites, conseguiu-se implantar e conduzir estruturas e processos, revelando tendência para alcançar o que foi proposto.
\end{abstract}

PALAVRAS-CHAVE Administração hospitalar; Avaliação em saúde; Humanização da assistência.

ABSTRACT This article is a case study to evaluate the management experience of Municipal Public Motherhood of Betim (MG), between 2009 and 2011, by means of intervention analysis, that investigates whether objectives and goals proposed by the experience were achieved. The methodology consisted of document analysis and focus groups. The data analysis was guided on critical hermeneutics. The Motherhood adopted, during the study period, a management model interlaced to the care model, generating spaces of listening and accountability for the work processes. This study showed that, despite the limitations, it was found that deploy and conduct structures and processes, revealing a tendency to reach goals.

KEYWORDS Hospital administration; Health evaluation; Humanization of assistance.

'Pontifícia Universidade Católica de Minas Gerais (PUC-Minas) - Betim (MG) Prefeitura Municipal de Betim - Betim (MG), Brasil. adrianadedeus@oi.com.br

2 Universidade Federal de Minas Gerais (UFMG),

Escola de Medicina - Belo Horizonte (MG), Brasil.

elzamelo@medicina.

ufmg.br 


\section{Introdução}

Ao longo dos últimos anos tem se observado grandes mudanças nas orientações políticas, nas formas de financiamento e nas diretrizes em relação à organização das redes de serviço e do modelo de gestão e atenção adotado pelo Sistema Único de Saúde (SUS). Tal modelo entendido como identificação dos traços principais de uma racionalidade que combina estruturas e tecnologias orientadas para as ações de saúde (PAIM, 2008).

Acompanhando o processo de organização de um novo modelo de atenção à saúde, fundado na concepção de um sistema integrado de serviços que deve interligar ações de prevenção, promoção e reabilitação com a atenção curativa e ter na atenção básica de saúde o centro deste sistema e a porta de entrada preferencial (PAIM, 2008), o hospital tem sido alvo de notórias mudanças, tanto nos aspectos referentes à redefinição do seu papel neste sistema de atenção à saúde, como na sua reorganização interna de trabalho, com o surgimento de novos modelos de gestão hospitalar (BRAGA NETO; BARBOSA; SANTOS, 2008).

Existe consenso em relação à necessidade do aprimoramento da gestão, da organização e do modo de funcionamento dos hospitais brasileiros, porém há uma variedade de caminhos sugeridos. A maioria das experiências é balizada por teorias, metodologias e técnicas administrativas que visam à eficiência e eficácia com utilização de mecanismos poderosos de controle dos processos de trabalho, avaliação de resultados com base na acreditação hospitalar e separação entre quem planeja e quem realiza as atividades com nítida centralização normativa e descentralização executiva (AZEVEDo ET AL., 2010).

Porém, vários autores como Campos (2007), Merhy (2007), Cecílio e Merhy (2003), dentre outros, reconhecem que esse pensamento gerencial hegemônico apresenta dificuldades para dar conta dos complexos desafios da gerência hospitalar, principalmente por tentar controlar o trabalho com métodos disciplinares, que não consideram as questões subjetivas e intersubjetivas que o permeiam e o constituem como "espaço de relação que se produz no encontro de sujeitos" (MERHY; ONOKO, 1997, P. 132).

Nesses espaços de interação, nos quais o profissional de saúde detém um alto grau de capacidade decisória, sustentada no saber técnico e onde o desempenho do gerenciamento disciplinar mostra-se insuficiente, abrem-se possibilidades para a adoção de outras estratégias pautadas na construção de novos valores e no estabelecimento de novas relações entre trabalhadores e usuários, que resultem na defesa da vida dos indivíduos e das populações (MERHY, 2007). A gestão, portanto, além de utilizar ferramentas e metodologias administrativas, passaria a considerar as relações e os interesses do conjunto de indivíduos e grupos envolvidos nos serviços de saúde (AZEVEDO ET AL., 2010).

Nessa perspectiva, a Política Nacional de Humanização (PNH) (BRASIL, 2008) propõe, por um lado, a utilização de dispositivos como as Linhas de Cuidado (CECílIO; MERHY, 2003), que valorizam a integração do hospital na rede de atenção e aprimoram a integralidade do cuidado e, por outro, a clínica ampliada, com a organização de equipes de referência e de matriciamento, e a elaboração de projetos terapêuticos interdisciplinares (CAMPOS; AMARAL, 2007). Propõe, também, um modelo de gestão estratégica pautado na gestão colegiada em todos os níveis de serviços, que, seguindo o conceito de cogestão (CAMPOS, 2007), amplia a capacidade dos trabalhadores, usuários e gestores para instituírem compromissos e atuarem na micro e macropolítica existentes na complexa tarefa de gerenciar o hospital (AZEVEDO ET AL., 2010).

Inúmeras dificuldades são encontradas no cotidiano do gerenciamento dos serviços hospitalares, devido a sua complexidade e ao enraizamento das práticas constituídas. Implantar modelos, programas ou ações condizentes com as diretrizes políticas e 
dispositivos preconizados pelo SUS, principalmente aqueles relacionados à efetividade do serviço, à gestão participativa e à valorização dos sujeitos envolvidos, são alguns dos desafios encontrados (BRAGA NETO; BARBOSA; SANTOS, 2008). Portanto, torna-se importante avaliar e analisar práticas dentro dos serviços de saúde que resultem no conhecimento dos limites, desafios e potencialidades, que consolidem modos de organizar tanto a atenção como a gestão e contribuam para o projeto democrático do SUS. "A construção conceitual e prática de um novo modelo é um desafio estratégico, diz respeito à viabilidade tanto econômica e política quanto sanitária do SUS" (CAMPOS, 2003, P. 109).

Este trabalho teve por objetivo avaliar a experiência de gestão da Maternidade Pública Municipal de Betim (MPMB), nos anos de 2009 a 2011, cuja escolha se deu pelo fato de que, neste período, a direção se propôs a implantar um novo modelo de gestão, orientado por objetivos que traduzissem para o cotidiano das organizações hospitalares as diretrizes e políticas do modelo de atenção e gestão hospitalar do SUS e da $\mathrm{PNH}$, segundo as proposições da teoria elaborada por Campos (2003) e outros autores (CECÍLIO; MERHY, 2003; MERHY; ONOKO, 1997).

A cidade de Betim, que em 2010 contava com uma população de 378.089 habitantes (IBGE, 2010), localiza-se na região metropolitana de Belo Horizonte, Minas Gerais. A Maternidade Pública Municipal de Betim Haideé Espejo Conroy é uma instituição pública de administração direta em funcionamento desde 08/05/1994, destinada ao atendimento do parto de risco habitual. Possui 55 leitos e, em 2010, com um quadro de 280 trabalhadores, realizava 896 atendimentos e 341 internações por mês (BETIM, 2010).

\section{Metodologia}

Trata-se de pesquisa avaliativa com enfoque teórico metodológico da pesquisa qualitativa em saúde, numa perspectiva crítico-reflexiva (MINAYO, 2008). Constitui estudo de caso, cujo objetivo foi avaliar a experiência de gestão da Maternidade por meio de análise da intervenção, isto é, analisar se os recursos e as atividades realizadas alcançaram seus objetivos planejados ou demonstraram tendências paraalcançá-los, sendo adequadamente conduzidos (HART, 2002). A pesquisa qualitativa foi escolhida por ser coerente com a natureza do objeto em questão e por possibilitar a compreensão das diferentes maneiras pelas quais os trabalhadores e gerentes revestiam de significado e formavam seus pontos de vista em relação aos vários aspectos da experiência vivida (FLICK, 2009).

Os procedimentos metodológicos utilizados para a obtenção do material empírico foram: a análise de vinte e sete documentos institucionais que "devem ser vistos como uma forma de contextualização da informação e analisados como dispositivos comunicativos metodologicamente desenvolvidos na construção de versões sobre eventos" (FLICK, 2009, P. 234); e a realização de grupos focais, pois além de possibilitarem as técnicas individuais, propiciam, na perspectiva do interacionismo simbólico, a valorização da comunicação e interação grupal (FLICK, 2009).

Foram organizados quatro grupos focais, com duração em média de uma hora e meia cada um, realizados na própria instituição, em novembro de 2012, com o total de trinta participantes. Dois grupos (G1, G2) foram formados por trabalhadores das diversas categorias profissionais. Outro grupo (G3) foi formado por trabalhadores que participam do Colegiado Ampliado. Por último, formou-se um grupo (G4) de gerentes da Maternidade, integrantes do Colegiado Gestor.

A escolha dos integrantes dos grupos, realizada de maneira intencional, considerou a habilidade do indivíduo de participar e contribuir com o conteúdo da discussão (FLICK, 2009). Foi utilizada a saturação teórica como fundamento para definição do número de grupos focais, tendo por 
referência o estágio em que o acúmulo subjetivo em relação aos objetivos já possibilitava a compreensão do objeto pesquisado, dentro dos limites do estudo.

Para análise dos dados dos grupos focais trabalhou-se com base nos pressupostos da hermenêutica dialética por possibilitar interpretar os dados, buscando a lógica interna dos fatos e dos relatos, situando-os no contexto dos atores e articulando-os com os objetivos do estudo, com a base teórica adotada (MINAYO, 2008).

Essa associação de procedimentos metodológicos com a utilização da análise documental e dos grupos focais com olhares de diferentes sujeitos aprimora a fidedignidade da pesquisa e permite abordar o objeto em seus diversos ângulos, ou seja, incorpora "os vários pontos de vista, garantindo a diversidade de sentidos expressos pelos interlocutores, fugindo à ideia de verdade única" (MINAYO, 2012, P. 625).
Cumpriram-se os preceitos éticos da pesquisa envolvendo seres humanos conforme o parecer número CAE 04784312.1.0000.5149 da comissão julgadora do Comitê de Ética em Pesquisa da instituição proponente deste estudo, como determinado pela Resolução $n^{\text {o }}$ 196/1996, do Conselho Nacional de Saúde (CONSELHO NACIONAL DE SAÚDE, 1996).

\section{Resultados e discussão}

Após estudo dos dados coletados na pesquisa, emergiram três categorias de análise: qualidade do cuidado, gestão participativa e produção de sujeitos, a partir das quais se fez a discussão.

\section{Qualidade do cuidado}

O modelo de cuidado foi implementado em março de 2010 com suas diretrizes, ferramentas e ações centradas nas usuárias (figura 1).

Figura 1. Modelo assistencial da Maternidade Pública Municipal de Betim

\section{Modelo Assistencial da Maternidade Pública Municipal de Betim}

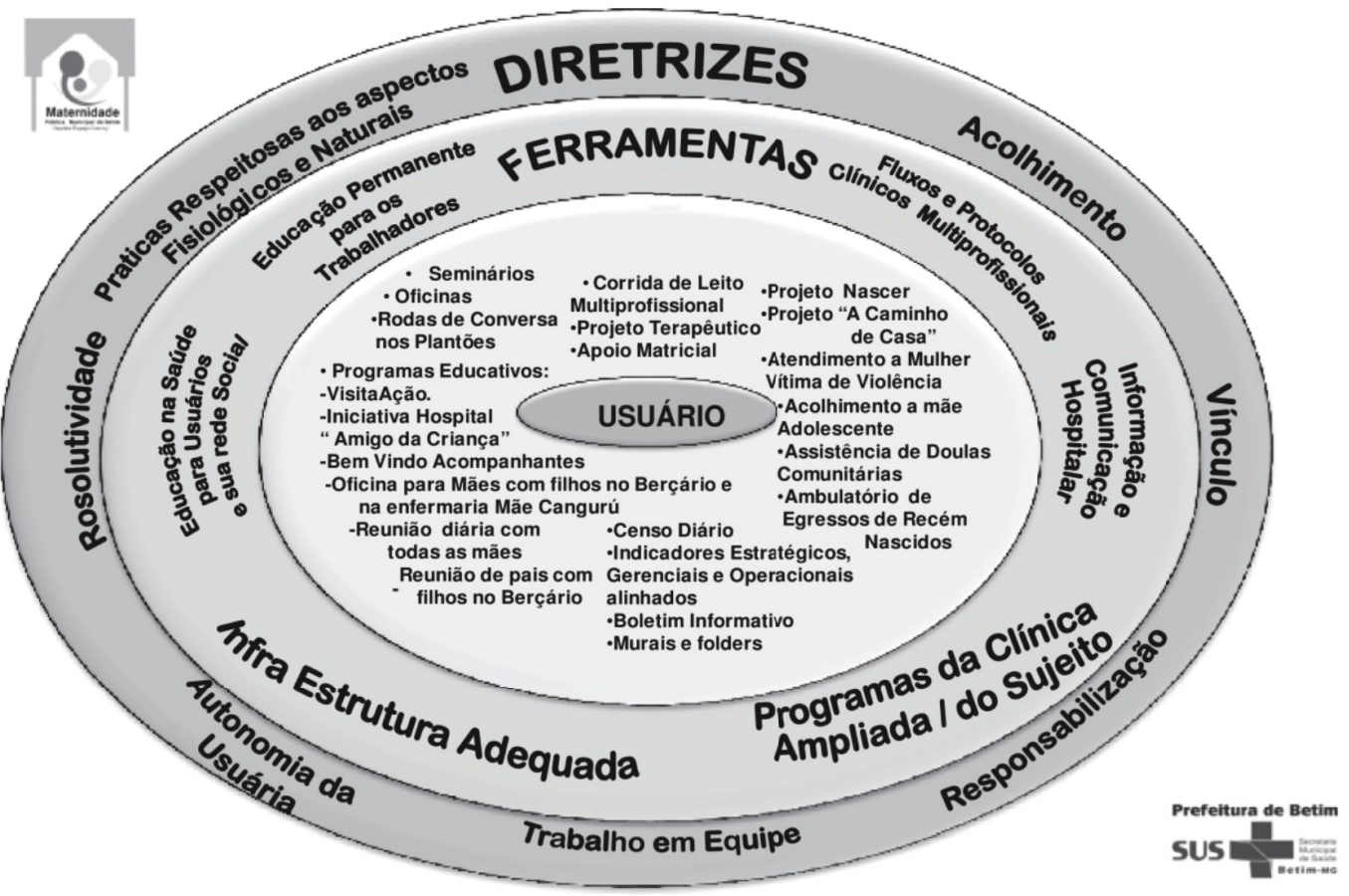


A Maternidade possui uma história de caminhada na perspectiva da qualificação da assistência, portanto, coube à gestão estudada retomar e aprimorar algumas propostas que foram perdidas nos últimos anos e implantar outras novas, sistematizando-as em um modelo único (BETIM, 2010).

Os participantes da pesquisa foram unânimes em reconhecer a qualidade do cuidado oferecido pelas equipes multiprofissionais, tanto no que diz respeito à competência técnica, aos programas da política de humanização implantados (BRASIL, 2008) e ao acolhimento respeitoso e atencioso. "É um tratamento excelente, a equipe é muito bem preparada, muito boa" (G1). "Em termos de humanização, eu não tenho nada a reclamar daqui, eu acho o projeto de atendimento muito bom. A Maternidade é nota 10 em relação a isto" (G1).

As falas revelam uma concepção de que o cuidado com a saúde da usuária é responsabilidade de todas as categorias, ou seja, todos os trabalhadores de saúde fazem clínica, entendida aqui no seu conceito amplo (MERHY, 2007), como espaço onde se opera o 'trabalho vivo em ato', ligado ao campo das relações, no qual o vínculo, a responsabilização e o acolhimento fazem parte do arsenal terapêutico (CAMPOS, 2003).

Quando ela [usuária] é bem recebida ali, ela passa daqui pra lá mais tranquila, né. E também aqui dentro com as meninas da enfermagem e com as doulas que dão um grande apoio, em um ambiente acolhedor. (G2).

Às vezes você chega lá na enfermaria, já me aconteceu, da paciente estar chorando e eu saí da copa e perguntei: o que é que aconteceu? E houve um desabafo ali, sabe? Então, não tem muita diferença de ser médico, enfermeira não. Acho que isso é qualidade, né? (G2).

Essa confiança dos trabalhadores na qualidade do cuidado oferecido é demonstrada quando eles utilizam os serviços oferecidos ou os indicam a parentes e amigos. "Eu trabalho aqui há dezesseis anos. Fui mãe e fui avó aqui, posso falar como funcionária e como usuária. Eu acho que melhorou muito sim o atendimento" (G1). "[...] quando um colega vem ganhar neném com a gente, é porque confia no trabalho da gente. Ele confia no trabalho que ele faz" (G2).

Segundo os profissionais, a população reconhece a qualidade da atenção oferecida na Maternidade, uma vez que procura o atendimento mesmo sendo de outros municípios e de outra área de abrangência.

[...] tanto que, às vezes tem paciente que nem é pra vir pra cá, que é de Contagem, que é de Belo Horizonte, que é do Regional, que é paciente de alto risco, né, mesmo assim querem vir pra cá porque alguém falou. É referência. (G1).

Vem crescendo, nesses últimos anos, a opinião de profissionais e gestores da área da saúde de que o gerenciamento de um hospital, em virtude de sua característica e complexidade, deva ser balizado por teorias, metodologias e técnicas administrativas, com a finalidade de qualificar os processos de trabalho e a atenção (BRAGA NETO; BARBOSA; SANTOS, 2008). Os documentos e os depoimentos evidenciam um gerenciamento mais profissionalizado, que utiliza estratégias e dispositivos originários de diversas abordagens conceituais, porém imersos em processos coletivos capazes de envolver gerentes e trabalhadores.

Foram elaborados a partir de 2009: os fluxos descritivos analíticos (MERHY; ONOKO, 1997, P. 73), os produtos, as metas, os indicadores de resultados e as tabelas de gerenciamento com indicadores de processos de todos os setores das Linhas de Cuidado e de Apoio; as Instruções Técnicas de Trabalho (ITT); os protocolos clínicos; os kits de medicamentos, de procedimentos e de rouparia; o 'Manual de normas internas dos direitos e deveres dos trabalhadores'; o 'Regimento interno da Maternidade'; a 
organização das comissões hospitalares; a Semana da Organização com investimentos na melhoria da ambiência em todos os setores; a implantação do censo hospitalar com a reorganização do 'Boletim informativo de indicadores' e sua divulgação para trabalhadores e usuários (BETIM, 2010).

Eu entendo que nesse período houve uma preocupação com a qualidade na saúde. Teve toda uma discussão e eu vi muito avanço [...] os serviços pararam para pensar cada processo de trabalho em fluxos. E a gente montou o caminho que a gestante faz dentro da Maternidade para que desse caminho a gente pudesse detectar tudo o que precisava melhorar, o que estava bom, o que tava ruim; foi quando a gente fez o curso de formação gerencial. [...] hoje tem controle maior e as pessoas usam mais os dados para avaliar e planejar. Hoje tem essa monitoria. (G3).

Em 2009, a Vigilância Sanitária Municipal elaborou o Termo de Obrigação a Cumprir (TOC), com sessenta e quatro irregularidades apontadas, assim, a diretoria da Maternidade construiu um 'plano de ação e monitoramento por cores' para realizar e acompanhar o cumprimento das correções necessárias. Em dezembro de 2010, a Maternidade conquistou seu alvará sanitário entregue em solenidade específica (BETIM, 2010).

Os trabalhadores da Maternidade reconhecem o empenho da gerência no investimento em infraestrutura, o que, para eles, resultou na melhoria das condições de trabalho e gerou um sentimento de valorização por parte do trabalhador.

[...] duas coisas positivas foram o empenho de conseguir os materiais, os instrumentos pra gente trabalhar e nossa gerente ter essa garra de estar buscando as melhores maneiras e condições da gente trabalhar. (G1).

No entanto, frequentemente, esse empenho perdia potência na lentidão dos processos de compras. Muito se tem discutido sobre a inadequação dos modelos de administração direta para gestão de hospitais (BRAGA NETO; BARBOSA; SANTOS, 2008; CAMPOS, 2007). A rigidez na execução orçamentária, a burocracia dos processos de investimentos e as grandes dificuldades na administração de pessoal foram alguns dos problemas encontrados.

Segundo os trabalhadores, houve melhorias na organização interna da gestão do trabalho.

Um ponto positivo foi a clareza nas definições das funções das Linhas de Cuidado, da função de cada funcionário. [...] Então assim, esse apoio, esse suporte, em função da organização [da gestão do trabalho] foi um ponto positivo. (G1). 


\section{Gestão participativa}

Figura 2. O modelo de gestão participativa foi implantado na Maternidade no início de 2009

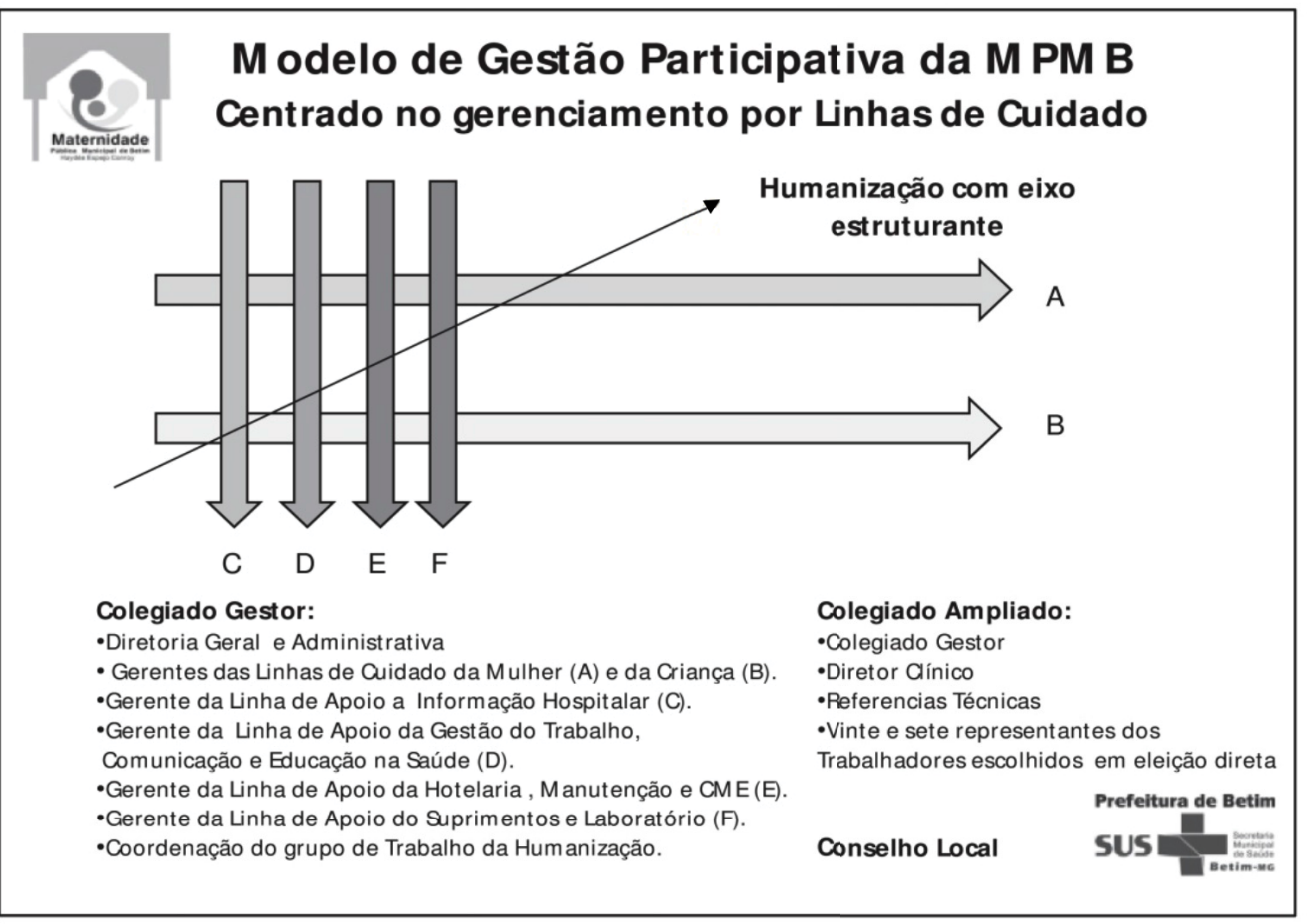

Fonte: Betim (2010)

Os gerentes das Linhas de Cuidado da Mulher e da Criança se responsabilizavam pelo trabalho de assistência, pela gestão dos profissionais que atuavam na respectiva Linha e pela interligação com a assistência realizada fora da Maternidade. Os gerentes das Linhas de Apoio coordenavam as atividades dos profissionais da sua Linha assegurando a infraestrutura necessária. O Colegiado Gestor, com suas reuniões semanais de caráter deliberativo, tinha como atribuição a negociação permanente, possibilitando contratos entre os gerentes das Linhas de Cuidado e de Apoio e a diretoria. O Colegiado Ampliado, de caráter consultivo e deliberativo, realizava reuniões mensais e era responsável por elaborar o planejamento de gestão da MPMB, discutir problemas, organizar estratégias para suas soluções e acompanhar sua execução. Gerentes e representantes dos trabalhadores e usuários participavam do Conselho Regional de Saúde, no qual discutiam soluções para os problemas de saúde da região (BETIM, 2010).

A metodologia elaborada para a formação do Colegiado Ampliado, por votação direta de representantes por setores, foi considerada como um fator que motivou os trabalhadores, ampliou a participação e distribuiu responsabilidades.

Houve uma votação, cada setor elegeu um funcionário que queria que fosse o seu representante [...] foi uma das coisas muito bonitas que aconteceu aqui, porque deu voz ativa, colocou todos os funcionários num mesmo nível de responsabilidade. (G2).

$\mathrm{Na}$ verdade, eu trabalho aqui há muito tempo, tinha coisas que aconteciam e que eu nem sabia que tinha. E foi através dos colegiados, dos trabalhos em grupo, misturando os colegas, que as coisas passaram a acontecer. (G3). 
Para os gerentes, o Colegiado Gestor possibilitou o compartilhamento dos problemas e a proposição de soluções conjuntas. Os momentos frequentes de avaliação e a metodologia das reuniões semanais colaboraram para formação, entrosamento da equipe e para o crescimento pessoal.

O que ajudou muito esse grupo foi a união. Mesmo nos momentos difíceis, mesmo nas discussões, às vezes um não concordando com o que o outro queria, no final, a gente estava unido. (G4).

Pessoalmente, eu vi que a gente cresce muito com o grupo. É muito bom porque você vai percebendo as qualidades de cada um e você vai tendo coragem também pra colocar em prática as coisas, isso é bom e vê que você dá conta também. (G4).

A participação dos trabalhadores no Colegiado Ampliado foi diminuindo a partir de 2011. Vários foram os motivos apontados nas falas dos trabalhadores: dificuldade em participar das reuniões marcadas fora do horário de serviço; impossibilidade de sair do plantão devido à alta demanda ou por falta de apoio dos colegas; falta de uma política de incentivo aos participantes; insuficiente implicação de alguns representantes dos trabalhadores com o projeto proposto; desapontamento com os cortes realizados pela Secretaria de Saúde; não valorização das falas dos trabalhadores durante as reuniões; frustração devido a não realização de todas as atividades planejadas e falta de objetividade e de encaminhamento das decisões discutidas (BETIM, 2011A). Como observado também em outros estudos (CEcílıo, 2010), alguns trabalhadores não reconheciam os colegiados como espaços efetivos de participação e decisão. Houve dificuldades de articulação entre os trabalhadores representantes que participavam do Colegiado Ampliado e seus representados, além da difícil comunicação das decisões tomadas tanto no Colegiado Ampliado quanto no Colegiado Gestor, para o conjunto dos trabalhadores. Apesar das tentativas de construir análises e soluções compartilhadas, os gerentes e trabalhadores consideram que o Colegiado Gestor não foi capaz de articular estratégias que possibilitassem solucionar esses problemas e manter a participação desses integrantes (BETIM, 2011A).

Teve uma avaliação do colegiado em 2011. Foram discutidos os maiores problemas que nós encontramos, né, o problema de comunicação, da representatividade, da informação. Aí faltou prosseguimento do trabalho, faltou reunião pra tratarmos destes assuntos de maior relevância. (G3).

Um Curso/Oficina de Formação Gerencial, de 14 meses de duração, foi oferecido pela diretoria em 2009, para os quarenta e sete membros do Colegiado Ampliado, utilizando-se de metodologias diversificadas e criativas. Com essa iniciativa, pretendia-se aprimorar os conhecimentos teóricos em gestão hospitalar dos participantes, motivar os trabalhadores para uma participação efetiva no gerenciamento, elaborar coletivamente as principais ferramentas de gestão e aperfeiçoar a organização dos processos de trabalho (BETIM, 2010). Na construção da democracia institucional é fundamental que se amplie a capacidade de gestão para o conjunto de pessoas e não a restrinja à alta direção. A socialização dessa habilidade diminui a distância entre gestores e trabalhadores e favorece a pactuação de compromissos (CAMPOS, 2007).

Ela [diretora] fez os cursos pra uma maior orientação, pra que essas pessoas fossem capacitadas, uma preparação pra que aqueles que estavam começando a participar, tivessem noção do que ia discutir. (G2). 
O Planejamento Estratégico e Operacional foi elaborado pelo Colegiado Ampliado durante o curso de Formação Gerencial, aprovado pela Secretaria Municipal de Saúde (SMS) e, posteriormente, discutido com os demais trabalhadores em Rodas de Conversa por plantão (BETIM, 2010). A elaboração conjunta do planejamento contribui com o diálogo e com o compartilhamento das ideias e propostas, consolida o senso de pertencimento e de corresponsabilidade e gera maior satisfação e realização pessoal (CAMPOS, 2007).

O Colegiado Ampliado soube fazer discussões dos principais problemas pra que a gente depois, junto com eles, criasse propostas. Claro que com isso a gente foi entendendo no mesmo instante as etapas de gerenciamento, né, de como fazer isso, ensinando a eles também. $E$ implicando a todos na questão da construção do Planejamento Estratégico que iria ser cumprido ao longo desses anos. (G4).

Ser reconhecida pelos usuários, funcionários e nacionalmente como uma maternidade que valoriza o trabalhador, realiza gestão participativa e possibilita à família vivenciar uma experiência feliz e segura do parto/nascimento (BETIM, 2010) foi a visão que norteou a elaboração das sete Diretrizes da Maternidade: a) implantar a gestão participativa; b) oferecer atendimento de qualidade e humanizado às usuárias e sua rede social; c) valorizar o trabalhador; d) organizar os processos de trabalho; e) adequar a infraestrutura conforme as normas da Agência Nacional de Vigilância Sanitária (Anvisa); f) integrar efetivamente a Maternidade na rede assistencial; g) otimizar os recursos financeiros. A partir dessas diretrizes foram planejadas trinta objetivos estratégicos e cento e cinquenta e quatro atividades (BETIM, 2010).

Avaliações periódicas das atividades do Planejamento Estratégico 2009/2012 foram realizadas por meio do monitoramento de indicadores e análises de cumprimento das tarefas programadas. Em dezembro de 2011:
$66 \%$ das atividades planejadas tinham sido cumpridas, $20 \%$ estavam em andamento e $14 \%$ estavam programadas. Estas avaliações foram discutidas e analisadas no Colegiado Ampliado e em seguida divulgadas entre os trabalhadores (BETIM, 2011B).

A democracia institucional depende da capacidade de se construírem espaços de poder compartilhado, que produzam tanto compromisso e solidariedade com o interesse público quanto capacidade reflexiva e autonomia dos trabalhadores (CAMPOS, 2007). Foram implantados dispositivos de participação para possibilitar encontros entre sujeitos, melhorar a integração interpessoal e incentivar análises da realidade. Dentre estes: A Hora do Encontro; Ginástica Laboral; Passeio Familiar; Alimentação Saudável: Saúde e Qualidade de Vida; Saúde e Coerência; Fala Cidadão; Grupo de Teatro; Grupo de Educação Ambiental; Grupo de Eventos; Núcleo de Educação Permanente; Aprimoramento na comunicação interna; Gestão porta aberta e o Grupo de Trabalho da Humanização (BETIM, 2010).

Os trabalhadores reconhecem que essas atividades melhoraram o relacionamento entre colegas, o entusiasmo e a motivação.

Foi um período de muita participação. E isso deu muita movimentação interna, pôs muitas meninas pra frente, então foi importante. A gente aprendeu muita coisa, a gente conseguiu passar muita coisa. (G1).

Porém, a partir de 2011, quando a SMS determinou cortes de pessoal, alguns desses grupos de trabalho foram extintos.

Começou muito bem, todo mundo empolgado. Mas com o tempo, eles foram cortando as horas extras, as extensões de jornada, então não tinham mais como promover aquilo. (G1).

Para além dos arranjos institucionais e dispositivos de participação, a gestão participativa acontece principalmente na capilaridade 
das relações e atitudes cotidianas. Gerenciar de um modo mais amplo do que o pautado no saber técnico administrativo e na atuação em resposta a demandas urgentes, pressupõe uma postura de incentivo à formação de coletivos, de escuta, de valorização do saber do outro, logo, a habilidade em manejar relações de conflito, mediar desejos e necessidades e, obviamente, exercer adequadamente a autoridade (CAMPOS, 2007).

[...] essa é uma gestão mais trabalhosa. Você fazer uma gestão participativa é uma gestão que você tem que saber lidar com visões diferentes, com opiniões diferentes, ter que lidar com o gerenciamento de conflito. (G4).

Os trabalhadores e gerentes reconhecem que houve dificuldades no desempenho dessas funções por parte de alguns gerentes (BETIM, 2011A) "Cada gerente é de uma forma, uma te recebe, outra te escuta, outras não querem nem saber do seu problema" (G1). Ao longo do tempo, alguns gerentes se tornaram líderes das equipes que coordenavam. "Então, depois dessa questão da gestão participativa, a nossa gerência mudou. Ela tem boa vontade de nos ouvir e tá trazendo a discussão feita no colegiado" (G1).

O gerenciamento se tornou um aprendizado diário, um esforço cotidiano de reflexão da prática.

Como em outros trabalhos (CECílIO; TANIELLA, 2004), aqui também se observa que os gerentes dispendem a maior parte do tempo na solução de problemas, 'apagando incêndios diários', restando pouco tempo para o planejamento e o monitoramento das ações na unidade sob sua responsabilidade, como também para o incentivo ao trabalho coletiVO (BETIM, 2011A).

$\mathrm{Na}$ trajetória desta experiência em análise, notam-se duas etapas distintas: a primeira durante os anos de 2009 e 2010 de intensa participação e construção coletiva; a segunda, a partir de 2011, quando ocorreram mudanças conjunturais que interferiram na gestão interna da Maternidade, inclusive, a saída da diretora geral, que assumia também a função de apoiadora, e sua substituição por um dos gerentes do Colegiado Gestor. Segundo Campos (2007), o apoiador da gestão participativa exerce função gerencial complementar de coordenação, planejamento, supervisão e avaliação do trabalho em equipe, que deve ser realizada de uma maneira interativa e democrática, reconhecendo a diferença de papeis, de poder e de conhecimento, procurando estabelecer relações construtivas, articulando os objetivos institucionais aos saberes e interesses dos trabalhadores, gerentes e usuários. Pelos depoimentos dos participantes, essa mudança trouxe impacto inicial para o processo em curso.

Eu acho que o grupo estava indo, mas não estava maduro suficiente para andar sozinho. Então, a saída dela [diretora] aconteceu na adolescência do grupo, sabe, que não tinha ainda uma maturidade pra dar continuidade e manter a atividade. (G3).

No inicio de 2011, a Prefeitura Municipal enfrentou a insatisfação dos trabalhadores com a reestruturação do Plano de Cargos, Contribuições e Vencimentos (PCCV), além de ter passado por restrições financeiras e dificuldades com o cumprimento da lei de responsabilidade fiscal. Portanto, foi preciso realizar cortes de pessoal na MPMB, cortes de serviços, diminuição das horas extras e das extensões de jornada, ocasionando desfalques de profissionais nas escalas de serviço, afetando a qualidade da assistência e do ambiente organizacional e consequentemente a gestão participativa (BETIM, 2011A).

Acabaram com as extensões, muita gente ficou muito chateada com os cortes do PCCV. Levamos um choque grande. Estas atitudes da prefeitura repercutiram muito aqui dentro. Ficamos muito desmotivados e atrapalhou a participação dos funcionários nas atividades. (G3). 
Algumas ações planejadas não puderam ser executadas e outras tiveram que ser desativadas, gerando sentimento de frustração nos trabalhadores e nos gerentes.

As pessoas esperavam que nós pudéssemos cumprir tudo aquilo que a gente tinha acordado com o colegiado [...] elas tiveram muita expectativa no início e a gente teve problema ao caminhar. (G4).

A SMS tinha como uma das suas diretrizes a gestão participativa, oferecendo, inclusive, apoio e estímulo à direção da Maternidade, durante a fase inicial da organização do modelo de gestão (BETIM, 2010). Porém, segundo a opinião dos gerentes, a SMS não conseguiu, principalmente a partir de 2011, acompanhar o trabalho interno da Maternidade, não soube lidar com as suas especificidades, como também não aprimorou metodologias capazes de atuar mais democraticamente nas decisões cotidianas.

A gente estava sendo muito desrespeitado [pela SMS] enquanto gestores. E no momento que a gente mais precisou, veio determinações de cortes de cima pra baixo. (G4).

Isto dificultou o trabalho do Colegiado Gestor que, por sua vez, não teve a habilidade de encaminhar aos trabalhadores e ao Colegiado Ampliado as discussões sobre esses conflitos com a SMS e sobre as decisões referentes aos cortes financeiros, o que, posteriormente, foi considerado pelos próprios gerentes um erro estratégico, pois desestimulou os trabalhadores e desacreditou a gestão participativa (BETIM, 2011A).

Mas tomar certas decisões da forma que a gente fez [sem discutir com o Colegiado Ampliado] ficou parecendo que a gente é que estava sendo desrespeitoso com eles [trabalhadores]. Então assim, muito difícil esse momento pra gente, foi muito dolorido. (G4).
Acho que isso foi um erro nosso, a gente ficou uns quatro meses sem reunir, a gente não tinha coragem de reunir porque a gente não dava conta de encarar o grupo de novo. (G4).

O gerenciamento tem a difícil função de articular as questões de governo, com a condução da organização e as necessidades e desejos dos vários atores em cena (AZEvedo et Al., 2010). Como observado, em muitas situações essa função 'sanduíche' é geradora de angústia.

Eu acho que a coisa mais difícil foi que a gente tava sendo cobrado pelos trabalhadores, e sendo cobrado pela Secretaria. Então, eu acho que o grupo se sentiu assim, encurralado. (G4).

Além disto, gerenciar os diversos interesses, afetos e poderes que se embaralham no cotidiano da instituição não é uma tarefa fácil e o desgaste torna-se maior quando os gerentes e diretoria são antigos trabalhadores da mesma instituição, como observado nesta experiência.

$E$ às vezes, você atendia um, mas tava prejudicando o outro. Então, a gente tinha que explicar as nossas atitudes e mostrar de uma forma respeitosa como resolver em favor de um bem comum, porque a nossa visão às vezes era diferente do trabalhador. (G4).

Uma parcela de trabalhadores, desde o início da gestão, não se apropriou dos espaços de participação, alguns por pertencerem ao grupo político de oposição à gestão municipal; outros, por indiferença, desinteresse, comodidade, incredulidade na proposta ou descrença na sua própria capacidade de colaborar com a gestão. "Então eu dizia, não vou entender o que eles estão falando, essas coisas lá de nível superior e tal, então eu não quis participar" (G2). "Tinha pessoas que poderiam ter participado mais, mas por causa da questão política não iam, isso também dificultou" (G2). "A gente acha muito mais tranquilo 
que a pessoa que está na direção traga tudo pronto. Acatar do que tomar decisão. Porque aí depois de qualquer coisa a gente fala: está vendo, foi ela" (G2).

Vários autores (CECílLI; TANIELLA, 2004; CARAPINHEIRO, 1998) abordam as dificuldades da categoria médica em realizar trabalho interdisciplinar e de ocupar espaços de participação na gestão dos serviços de saúde. $\mathrm{Na}$ MPMB não foi diferente.

A representatividade que a gente tem de médicos no colegiado ampliado é mínima. É uma equipe difícil de ser atingida. Os médicos não sabem o que e como estamos trabalhando. Existe um mundo além daquele quarto que os médicos não conhecem, não conhecem o resto da Maternidade. Eles só ficam ali, só se concentram ali, festejam ali, não sabem que tem um mundo aqui fora. É uma coisa impressionante! Tanta coisa acontecendo aqui e eles simplesmente não se importam. [...] a gente não conseguiu atingir efetivamente a equipe médica, mostrar a que viemos. A [diretora] fez reunião até dentro do quarto dos médicos com o cavalete [risos], já que eles não saem do quarto, nós fomos até o quarto deles, né? (G4).

Os depoimentos dos trabalhadores apontam qualidades na gestão participativa, qualificando-a inclusive como direito de cidadania. Para eles, a participação propicia um sentimento de pertencimento, aumenta o grau de adesão e execução das atividades planejadas e qualifica o trabalho. "A gestão participativa eu acho que é uma questão de educação, que começa lá na escola [...] É uma questão de cidadania” (G2).

$E$ isso teve efeito pro usuário, por que quando a gente sente fazendo parte, a gente acolhe melhor o usuário, tem mais vontade de fazer as coisas. Eu quero fazer o melhor porque eu também faço parte. (G2).

Para os gerentes, a gestão participativa possibilita a diversidade de pontos de vista, provocada pelos espaços de escuta, nem sempre tranquilos, entre pessoas que ocupam diferentes postos de trabalho, ampliando o diagnóstico da situação e apontando melhores soluções para os problemas.

Quem está lá atendendo, tem uma visão diferente de quem está gerenciando, de quem está na portaria e às vezes aparecem soluções de problemas de pessoas que você não imaginava, por isto assim, tem um lado muito bom, muito gratificante. (G4).

\section{Produção de sujeitos}

$\mathrm{Na}$ racionalidade gerencial hegemônica observa-se uma nítida separação entre o trabalho criativo, intelectual, de planejar, de conceber ideias e de decidir, realizado pela alta direção; e o trabalho alienado de mera execução das atividades, exercido pelos trabalhadores.

Essa racionalidade apoia-se em arranjos organizacionais de disciplina e controle, que educam os trabalhadores para submissão, conformismo, e para suposição de que não detêm saber e capacidade suficiente para contribuírem na gestão das instituições, restringindo espaços de manifestação das subjetividades, aproximando as pessoas à condição de objeto (CAMPOS, 2007).

Ah, mas eu dizia: não vou dar conta disso, é muito assunto que eu não vou entender. Muitos pensaram assim, e muitos não acreditaram nessa capacidade, nesse poder de ser sujeito, né, acabam muitas vezes na crítica, porque as pessoas não entendem, ou entendem, mas não acreditam que isto pode fazer a diferença. (G2).

Esta experiência de gestão propôs reorganizar, de modo participativo, as práticas gerenciais, contribuindo dessa forma para a produção de sujeitos (CAMPOS, 2007; CAMPOS, 2003), aqui entendidos como aqueles capazes de descobrir significados, criar sentidos, 
elaborar conceitos, ideias e atuar no mundo de maneira ativa e reflexiva (CHAUÍ, 1994).

\section{[...] teve um momento de reflexão sim. Pra todo} mundo teve essa marca, que teve alguém que fez você pensar que as coisas podem ser vistas por outra forma, que você pode contribuir e se quiser pode fazer. (G2).

Nota-se que houve um grande esforço por parte da gerência em propiciar práticas voltadas para ampliar a capacidade de análise das pessoas e sua compreensão da realidade, promovendo autonomia na gestão das suas próprias vidas e das instituições onde atuavam. Capacidade de análise entendida como análise do contexto, análise dos próprios interesses e desejos e análise das propostas de intervenção. Análise para possibilitar maior iniciativa e atuação no mundo, seja por meio da política, da gestão de organizações ou do cuidado com a própria saúde (CAMPOS, 2003).

Ela [uma trabalhadora que participou do colegiado ampliado] é uma pessoa realmente importante, mas pra ela isso mexeu na autoestima, gente, isso melhorou a vida dela também, entendeu, a vida dela particular mudou pela autoestima que tudo isso levou a ela, sabe. Eu acredito que mexeu com todos nós. (G2).

Então isso mexe com as pessoas, mexe com essa questão de ser sujeito e você começa a pensar assim: eu posso com as minhas atitudes mudar alguma coisa. A gestão participativa faz isso, né? (G2).

Observa-se nos depoimentos, de trabalhadores e gerentes, que este processo coletivo, para aqueles que participaram, possibilitou o exercício da práxis, atuar segundo finalidades, construindo o sentido e o significado para a ação, agir sobre o mundo de modo reflexivo, alterando o agente junto com a reconstrução do contexto (CHAUI, 1994), contribuindo para o crescimento pessoal.
Acho que de uma forma indireta, as pessoas já falaram sobre isto. De como modificaram a visão das coisas e como houve enriquecimento pessoal, sobre a importância do seu trabalho e do trabaIho do outro, né. Eu vejo que nessa questão do ganho pessoal é impressionante! Quem participou participando mesmo, eu não tenho dúvida que teve enriquecimento pessoal. Essa é a parte melhor. (G3).

\section{Considerações finais}

Este estudo avaliou a experiência de gestão da MPMB, que apostou no modelo de gestão participativa, articulado ao modelo de cuidado, gerador de espaços de escuta, troca de informações, planejamentos, decisões, compromissos e de corresponsabilização pelos processos de trabalho e seus resultados. Acreditando que nesses espaços expressam-se desejos, afetos, interesses e poderes, capazes de produzir sujeitos mais autônomos e mais comprometidos com os interesses coletivos. No curto espaço de tempo, apesar dos limites e dos inúmeros desafios, verificou-se que essa gestão conseguiu implantar e conduzir as estruturas e processos, revelando tendência de alcançar os objetivos propostos. Pode-se concluir que o modelo adotado propiciou um cuidado de saúde humanizado e de maior qualidade; ampliou a participação dos profissionais na gestão e promoveu maior interação entre eles; estimulou a práxis da autonomia e, por decorrência, contribuiu para o desenvolvimento da democracia institucional, todos esses sendo, sem dúvida, fatos de grande relevância para o sistema de saúde e para a população. Não por acaso, esta experiência obteve reconhecimento nacional ao ser classificada em primeiro lugar da sua categoria para o Prêmio Nacional Sérgio Arouca/Experiências Exitosas em Gestão Participativa, oferecido pelo Ministério da Saúde, Conselho Nacional de Secretários de 
Saúde e Conselho Nacional de Secretários Municipais de Saúde, em 2011.

Esta gestão constituiu, certamente, uma oportunidade ímpar de aprendizagem para todos que se envolveram cotidianamente no projeto coletivo. A avaliação e a sistematização dessa experiência contribuíram, por sua vez, para ampliar e divulgar o conhecimento e promover a reflexão crítica sobre o modo de operar, 'o como fazer'. Por fim, a experiência e sua avaliação, no conjunto, representam exemplos de concretização de propostas de gerenciamento dos serviços de saúde, segundo aspectos como gestão participativa, valorização dos sujeitos envolvidos e assistência qualificada, que contribuem para a radicalização do projeto democrático do SUS.

\section{Referências}

AZEVEDO, C. S. et al. Caminhos da organização e gestão do cuidado em saúde no âmbito hospitalar brasileiro. Política, planejamento e gestão em saúde. Rio de Janeiro. Abrasco, v. 1, n. 11, p. 95-116, 2010.

BETIM. Maternidade Pública Municipal de Betim. Colegiado Gestor. Relatório de Gestão 2009/2010. Betim, 2010. (documento interno).

. Maternidade Pública Municipal de Betim. Colegiado Gestor. Relatório da oficina de avaliação do Colegiado Ampliado em agosto de 2011. Betim, 2011a. (documento interno).

Maternidade Pública Municipal de Betim. Colegiado Gestor. Relatório de gestão 2011. Betim, 2011b. (documento interno).

BRAGA NETO, F. C.; BARBOSA, P. R.; SANTOS, I. S Atenção hospitalar: evolução histórica e tendências. In: GIOVANELLA, L. et al. Politicas e sistemas de saúde no Brasil. Rio de Janeiro: FIOCRUZ, 2008. cap. 18, p. 665-704.

BRASIL. Ministério da Saúde. Secretaria Executiva. Núcleo Técnico da Política Nacional de Humanização. Humaniza Sus. Documento base para gestores e trabalhadores do SUS. Brasília, DF: Ministério da Saúde, 2008.

CAMPOS, G. W. Um método para análise da co-gestão de coletivos. 3. ed. São Paulo: Hucitec, 2007.

Reforma política e sanitária: a sustentabilidade do SUS em questão? Ciência e Saúde Coletiva, Rio de Janeiro, v. 12, n. 2, p. 301-306, 2007.

Saúde Paidéia. São Paulo: Hucitec, 2003.
CAMPOS, G. W. S.; AMARAL, M. A. A clínica ampliada e compartilhada, a gestão democrática e redes de atenção como referenciais teórico-operacionais para a reforma do hospital. Ciência \&t Saúde Coletiva, Rio de Janeiro, v. 12, n. 4, p. 849-859, jul./ago. 2007.

CARAPINHEIRO, G. Saberes e poderes no hospital: uma sociologia dos serviços hospitalares. Porto: Edições Afrontamento, 1998.

CECÍLIO, L. C. O. Colegiados de gestão em serviços de saúde: um estudo empírico. Cadernos de Saúde Pública, Rio de Janeiro, v. 26, n. 3, p. 557-566, mar. 2010.

CECÍLIO, L. C. O.; MERHY, E. E. A integralidade do cuidado como eixo da gestão hospitalar. São Paulo: Hucitec, 2003.

CECÍLIO, L. C. O.; TANIELLA, C. M. Propostas alternativas de gestão hospitalar e o protagonismo dos trabalhadores: por que as coisas nem sempre acontecem como os dirigentes desejam? Saúde e Sociedade, Rio de Janeiro, v. 13, n. 2, p. 39-55, 2004.

CHAUÍ, M. Convite à filosofia. São Paulo: Ática, 1994.

CONSELHO NACIONAL DE SAÚDE. Resolução $n^{\circ} 196$ de 10 de Outubro de 1996. Dispõe sobre os principais documentos internacionais que emanaram declarações e diretrizes sobre pesquisas que envolvem seres humanos. Disponível em: <http://conselho.saude.gov. br/web_comissoes/conep/aquivos/resolucoes/23_ out_versao_final_196_ENCEP2012.pdf >. Acesso em: 18 maio 2013.

FLICK, U. Introdução à pesquisa qualitativa. 3. ed. Porto Alegre: Artmed, 2009. 
HART, Z. M. A. (Org.). Avaliação em saúde: dos modelos teóricos à prática na avaliação de programas e sistemas de saúde. Salvador/Rio de Janeiro: Fiocruz/Edufba, 2002.

\section{INSTITUTO BRASILEIRO DE GEOGRAFIA E} ESTATÍSTICA (IBGE). Censo 2010. População de Betim em 2010. Disponível em: < http://www.ibge. gov.br/home/estatistica/populacao/censo2010/tabelas_pdf/total_populacao_minas_gerais.pdf $>$. Acesso em: 15 jul. 2011.

MERHY, E. E. Saúde: a cartografia do trabalho vivo. 3. ed. São Paulo: Hucitec, 2007.

MERHY, E. E.; ONOKO, R. Agir em saúde: um desafio para o público. São Paulo: Hucitec, 1997.
MINAYO, M. C. S. Análise qualitativa: teoria, passos e fidedignidade. Ciência e Saúde Coletiva, Rio de Janeiro, v. 17, n. 3, p. 621-626, mar. 2012.

\section{O desafio do conhecimento: pesquisa qualitativa}

em saúde. 11. ed. São Paulo: Hucitec, 2008.

PAIM, J. S. Modelos de Atenção à Saúde no Brasil. In: GIOVANELLA, L. et al. Políticas e sistemas de saúde no Brasil. Rio de Janeiro: Fiocruz, 2008. p. 547-573.

Recebido para publicação em novembro de 2014

Versão final em junho de 2015

Conflito de interesse: inexistente

Suporte financeiro: não houve 